\title{
IN VIVO ANALYSIS OF THE EFFECT OF NANOSTRUCTURED LIPID CARRIER-BASED GEL OF MULBERRY ROOT EXTRACT AGAINST ULTRAVIOLET LIGHT
}

\author{
FAIZATUN FAIZATUN ${ }^{1}$, EFFIONORA ANWAR ${ }^{2 *}$, LIZA INDAH MERDIYAH ${ }^{1}$
}

${ }^{1}$ Department of Pharmacy, Faculty of Pharmacy, Universitas Pancasila, 12640, Jakarta, Indonesia. ${ }^{2}$ Department of Pharmacy, Faculty Pharmacy, Universitas Indonesia, 16424, Depok, Indonesia. Email: effionora.anwar@farmasi.ui.ac.id

Received: 21 June 2018, Revised and Accepted: 19 October 2018

\section{ABSTRACT}

Objective: This study aimed to analyze the in vivo anti-ultraviolet (UV) activity of nanostructured lipid carrier (NLC) of mulberry extract on six New Zealand rabbits.

Methods: Mulberry roots were treated with $96 \%$ ethanol using a maceration-ultrasonication method, and the extract was transformed into NLCs using the solvent evaporation method. The NLC was characterized for particle size and polydispersity index and zeta potential. The morphology of nanoparticles was examined using transmission electron microscope and subsequently in the NLC-based gel preparation. The gel was evaluated in vivo for anti-UV activity on male rabbits in three treatment groups: Positive control, sample gel, and negative control (exposed to UV light for $6 \mathrm{~h}$ ). The anti-UV activity was scored as a skin erythema response using Dermalab ${ }^{\circledR}$, and the results were analyzed using Kruskal-Wallis and Mann-Whitney methods.

Results: The particle size, polydispersity index, and zeta potential of the NLC were quantified as $203.2 \mathrm{~nm}, 0.264$, and $-38.7 \mathrm{mV}$, respectively. The viscosity of the gel was $42,500 \mathrm{cps}$, with pseudoplastic thixotropic flow properties including the spreading ability, particle size $5156.81 \mathrm{~mm}$, and $\mathrm{pH} 5.92$, respectively. The anti-UV activity was determined as $0.22,1.44$, and 2.22 for the positive control, NLC-based gel, and negative control groups, respectively.

Conclusion: The anti-UV activity of NLC-based gel of mulberry root extract was very small on areas where erythema had formed and differed significantly between the positive and negative control groups $(\mathrm{p}<0.05)$.

Keywords: Mulberry root, Morus alba L, Sunscreen, Nanostructured lipid carrier, Erythema value.

(C) 2018 The Authors. Published by Innovare Academic Sciences Pvt Ltd. This is an open access article under the CC BY license (http://creativecommons. org/licenses/by/4. 0/) DOI: http://dx.doi.org/10.22159/ijap.2018.v10s1.57

\section{INTRODUCTION}

Mulberry (Morus alba L.) root extracts have been widely used as an antiviral, antityrosinase, antioxidant, antitumor, and neuroprotective agent; it is also reported to prevent damage to DNA [1-6]. Some mulberry roots contain stilbenoids and polyphenols [3]. The stilbene and polyphenol derivatives in mulberry have been studied in leaves, branches, stems, and roots and occur in the highest concentration in roots [7].

Several classes of active antioxidant compounds such as flavonoids, tannins, anthraquinones, and cinnamate have been reported to protect against ultraviolet (UV) light [8]. Flavonoids protect against UV light due to the presence of chromophore groups. A chromophore group is a conjugated aromatic system that absorbs both UV A-long wave and UV B-short wave [8]. The use of antioxidants in sunscreen preparations is reported to boost the photoprotective activity of the sunscreen, thus preventing various illnesses caused by UV irradiation.

In this study, we aimed to transform mulberry root extract into nanostructured lipid carriers (NLCs). An NLC is a drug delivery system consisting of a mixture of solid and aqueous lipids, in which the active ingredient is absorbed into a surfactant-stabilized lipid matrix. The mixture of solid and aqueous lipids was chosen because it is a modified form of solid lipid nanoparticle, in which the aqueous lipids will disrupt the perfect structure of the solid lipids, resulting in an imperfect matrix that enables the active ingredient to be further absorbed into the carrier lipid. Using a lipid form of nanoparticle preparation has several advantages; it increases the amount of drug load, minimizes damage to the active compound during storage, has a high effectiveness, and does not cause irritation to the topical application [9]. Furthermore, we examine the in vivo anti-UV activity of the NLC of mulberry root extract with erythema observation on the skin of test animals in response to UV.

\section{MATERIALS AND METHODS}

Materials

Stearic acid (SA) (Sumi Asih Oleochemical Industry, Indonesia) was used as the solid lipid in the NLC, whereas virgin coconut oil (VCO) (Herba Bagoes Company, Indonesia) was used as an aqueous lipid in the NLC. Plantacare ${ }^{\circledR} 1200$ UP (BASF, Germany), Carbopol 940 (Lubrizol, USA), triethanolamine (Lubrizol, USA), propylene glycol (Dow Chemical, USA), methylparaben and propylparaben (Ueno Fine Chemical, Thailand), Uvinul ${ }^{\circledR}$ MC 80 (BASF, Germany), and ethanol (Merck, Germany) were purchased for the indicated manufacturers.

\section{Preparation of mulberry root extract}

Mulberry roots were macerated and subjected to ultrasonication using ethanol $96 \%$ solvent (Merck, Germany) at ratio mulberry root:ethanol 1:5. Maceration of root extracts was repeated 3 times. The extract was concentrated using a rotary vacuum evaporator.

\section{Formulation of NLC}

The NLC was prepared through the solvent diffusion method in an aqueous system. The mulberry root extract was dissolved in acetone, mixed with SA-VCO, and incubated in a water bath at $70^{\circ} \mathrm{C}$. The aqueous phase was prepared by dissolving Plantacare ${ }^{\circledR} 1200$ UP in distilled water at $70^{\circ} \mathrm{C}$. Subsequently, the organic phase was quickly dispersed into the aqueous phase with magnetic stirring at $600 \mathrm{rpm}$, followed by stirring with an Ultra-Turrax at 20,000 rpm. After removing the 
organic solvent, semi-transparent NLC was obtained, which was then transferred into cold distilled water $\left(0^{\circ} \mathrm{C}-2^{\circ} \mathrm{C}\right)$. The NLC was stirred for $5 \mathrm{~s}$ and then subjected to ultrasonication at $50 \mathrm{~W}$ for $15 \mathrm{~s}$.

\section{Physicochemical characterization of NLC}

\section{Particle size and zeta potential measurement}

The NLC was diluted 20 -fold using distilled water. The average diameter volume and zeta potential of the NLC in dispersion were determined using Zetasizer (2000HS, Malvern Instruments, UK).

\section{Morphology}

The NLC microstructure was observed using transmission electron microscope (TEM; JEM-1400, JEOL, Japan). First, samples diluted with double-distilled water were deposited on a film-coated copper grid. Then, samples were stained with $1 \%$ aqueous solution of phosphotungstic acid. Finally, the superfluous phosphotungstic acid on the samples was wiped off using filter paper, and the sample was allowed to dry before examining under the TEM.

\section{Formulation of NLC-based gels}

On the basis of the compatibility with nanoparticulate dispersion, carbopol 940 was selected as the gelling agent to prepare NLC-based gels. Carbopol 940 was dispersed using an overhead stirrer at the speed of $300 \mathrm{rpm}$. The carbopol dispersion was neutralized using $0.3 \%$ (w/w) triethanolamine. Carbopol $940(0.3 \%)$ was added to the NLC while continued overhead stirring at $300 \mathrm{rpm}$ until it was fully dispersed. Methylparaben and propylparaben were dissolved in propylene glycol, and this solution was mixed with the gel. The resulting NLC-based gel was characterized for its physicochemical properties, including viscosity, spreadability, flow, and $\mathrm{pH}$.

\section{In vivo anti-UV activity of the NLC-based gel}

To evaluate the anti-UV activity of the NLC-based gel in vivo, the development of erythema was observed on the skin of male rabbits (strain New Zealand) exposed to UV light for a certain time. This rabbits were 8 months old and weighed 3-4 kg. Rabbits were divided into three groups: Positive control, treated with Uvinul ${ }^{\circledR} \mathrm{MC}$ 80; negative control,

Table 1: Particle size and polydispersity index of NLC mulberry root extract

\begin{tabular}{lll}
\hline $\begin{array}{l}\text { Mixed lipid (SA-VCO): } \\
\text { Plantacare }{ }^{\circledR} \mathbf{2 0 0 0} \text { UP }\end{array}$ & Size (nm) & Polydispersity index \\
\hline $2: 2$ & 231.2 & 0.393 \\
$2: 2.5$ & 203.5 & 0.264 \\
$2.5: 2$ & 281.1 & 0.255 \\
\hline
\end{tabular}

SA-VCO: Stearic acid-virgin coconut oil, NLC: Nanostructured lipid carrier

Table 2: List of average erythema scores of test rabbits in three treatment groups

\begin{tabular}{ll}
\hline Treatment group & Average score \\
\hline Control positive & 0.22 \\
Test preparation & 1.44 \\
UV exposure only & 2.22 \\
\hline
\end{tabular}

treated with UV light only; and test preparation. The hair was shaved before applying the test preparation. The test preparation was applied for $1 \mathrm{~h}$, followed by exposure to a UV lamp for $6 \mathrm{~h}$. Subsequently, the test animals were cleansed, and the development of erythema was monitored at 1,24 , and $48 \mathrm{~h}$ after UV exposure using the Dermalab ${ }^{\circledR}$ combo.

\section{RESULTS}

\section{Preparation NLC of mulberry root extract}

The NLC of mulberry root extract was prepared using the solvent diffusion method in an aqueous system, with variable lipid:surfactant ratios of 2.0:2.0, 2.0:2.5, and 2.5:2.0. The morphology of the NLC mulberry root extract is shown in Fig. 1, and its properties, including volume, average diameter, and polydispersity index, are listed in Table 1.

In vivo analysis of the anti-UV activity of the NLC-based gel showed that the erythema scores of the positive control group, test preparation, and negative control (UV irradiation only) were $0.22,1.44$, and 2.22, respectively (Table 2). The determination of erythema value using Dermalab $^{\circledR}$ combo is shown in Table 3 .

Erythema scores of 0,1 , and 2 indicate no erythema, very little erythema, and moderate-to-severe erythema, respectively.

Statistical analysis of the quantitative measurement of erythema using Dermalab $^{\circledR}$ combo was performed using the Mann-Whitney method (Table 4).

\section{DISCUSSION}

The polydispersity index of the NLC has a maximum value of 1.0. A polydispersity index value of 1 indicates that the sample has a very large size distribution and contains large particles or aggregates capable of slowing sedimentation. The polydispersity index values of the three NLC formulations were $<1$, suggesting a narrow size distribution and small particles, thus obstructing sedimentation. A lipid:surfactant ratio of 2.0:2.5 yielded the smallest NLC size of $203 \mathrm{~nm}$, polydispersity index of 0.264 , and zeta potential of $-38.7 \mathrm{mV}$. The morphology of this NLC formulation was spherical (Fig. 1).

Physicochemical characterization of the NLC-based gel revealed a viscosity of $42,500 \mathrm{cps}$ and pseudoplastic thixotropic flow properties, including spreading ability and $\mathrm{pH}$ of $5156.81 \mathrm{~mm}$ and 6.12, respectively. The NLC-based gel was prepared by dispersing the NLC mulberry root extract in $0.3 \%$ carbopol 940 gel base. The NLC-based gel was light yellow in color, viscous, odorless, and homogeneous.

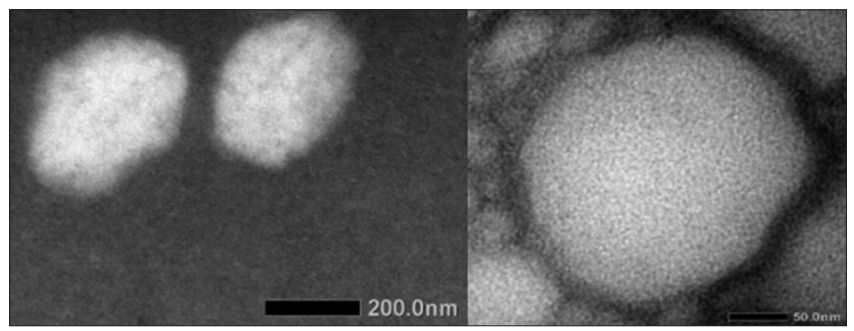

Fig. 1: Transmission electron microscopy micrographs of nanostructured lipid carrier mulberry root extract

Table 3: Erythema values using Dermalab ${ }^{\circledR}$ combo

\begin{tabular}{llll}
\hline Treatment group & Erythema value & & \\
\cline { 2 - 4 } & Before radiation & $\mathbf{1}$ h after radiation & 24 h after radiation \\
\hline Control positive & $6.1 \pm 0.32$ & $8.2 \pm 0.56$ & $10.6 \pm 1.65$ \\
Test preparation & $6.0 \pm 0.32$ & $11.85 \pm 0.86$ & $14.68 \pm 1.19$ \\
UV exposure only & $6.1 \pm 0.30$ & $13.75 \pm 0.78$ & $16.20 \pm 1.34$ \\
\hline
\end{tabular}


Table 4: Statistical analysis of erythema values using the Mann-Whitney method

\begin{tabular}{|c|c|c|}
\hline Statistical analysis & p value & Result \\
\hline $\begin{array}{l}\text { Control positive versus UV exposure } \\
\text { only }\end{array}$ & 0.001 & Significantly different \\
\hline $\begin{array}{l}\text { Control positive versus test } \\
\text { preparation }\end{array}$ & 0.004 & Significantly different \\
\hline $\begin{array}{l}\text { Test preparation versus UV exposure } \\
\text { only }\end{array}$ & 0.048 & Significantly different \\
\hline Before radiation versus $1 \mathrm{~h}$ & 0.000 & Significantly different \\
\hline Before radiation versus $24 \mathrm{~h}$ & 0.000 & Significantly different \\
\hline Before radiation versus $48 \mathrm{~h}$ & 0.000 & Significantly different \\
\hline
\end{tabular}

UV: Ultraviolet

The negative control group, which was exposed to UV light only, showed significantly higher erythema response than the positive control and test preparation groups $(\mathrm{p}<0.05)$. The test preparation group showed significantly higher erythema than the positive control group. Overall, the anti-UV activity of the three treatment groups showed the following order: Positive controls $>$ test preparations > negative controls (UV exposure only). In addition, erythema observations at different time points $(1,24$, and $48 \mathrm{~h})$ after irradiation showed significant differences $(\mathrm{p}<0.05)$.

\section{CONCLUSION}

In this study, spherically shaped NLCs of mulberry root extracts were produced with a particle size of $203.5 \mathrm{~nm}$, polydispersity index of 0.264 , and zeta potential of -38.7 . The NLC-based gel extract of mulberry roots was odorless and homogeneous and exhibited a yellow color. Its viscosity was $42,500 \mathrm{cps}$, and spreading ability was $5156.81 \mathrm{~mm}$. In addition, in vivo anti-UV activity of the NLC-based gel was observed by monitoring the occurrence of erythema on the skin of male rabbits exposed to UV irradiation. The strength of anti-UV activity in vivo followed the order: Positive control > test preparation > negative control
(UV exposure only). Erythema occurs because of the vasodilation of blood vessels in the dermis. Direct exposure to UV light for a prolonged time (6-20 h) causes vascular endothelial vasodilation, which increases the risk of the release of inflammatory mediators and mast cell vasoactive substances.

\section{CONFLICTS OF INTEREST}

All authors have none to declare.

\section{REFERENCES}

1. Chillemi R, Sciuto S, Spatafora C, Tringali C. Anti-tumor properties of stilbene-based resveratrol analogues: Recent results. Nat Prod Commun 2007;2:499-513.

2. Kim YM, Yun J, Lee CK, Lee H, Min KR, Kim Y, et al. Oxyresveratrol and hydroxystilbene compounds. Inhibitory effect on tyrosinase and mechanism of action. J Biol Chem 2002;277:16340-4

3. Zafar MS, Muhammad F, Javed I, Akhtar M, Khaliq T, Aslam B, et al. White mulberry (Morus alba): A brief phytochemical and pharmacological evaluations account. Int J Agric Biol 2013;15:612-20.

4. Faizatun F, Asto SD. In vitro determination of sun protection factors on ethanol extract and nanostructured lipid carrier-based gel extract of mulberry root (Morus alba L.). Asian J Pharm Clin Res 2018;11:138-40.

5. El-baz F, Hassan AZ, Abd-alla HI, Aly HF, Mahmoud K. Phytochemical analysis, assessment of antiproliferative and free radical scavenging activity of Morus alba and Morus rubra fruits. Asian J Pharm Clin Res 2017;10:189-99.

6. El-baz FK, Aly HF, Abd-alla HI, Fayed DB. Therapeutic impact of berries (Morus alba and Morus rubra) fruit extract in regression of high-fat diet-induced cardiac dysfunction in rats. Asian J Pharm Clin Res 2018;11:314-20.

7. Zhou J, Li SX, Wang W, Guo XY, Lu XY, Yan XP, et al. Variations in the levels of mulberroside A, oxyresveratrol, and resveratrol in mulberries in different seasons and during growth. Sci World J 2013;2013:380692.

8. Bonina F, Lanza M, Montenegro L, Puglisi C, Tomaino A, Trombetta D, et al. Flavonoid as potential protective agent photo-oxidative skin damage. Int J Pharm 1996;145:87-94

9. Prasiddha JI, Laeliocattleya AR, Estiasih T Malignant MJ. Potential corn bioactive hair compound (Zea mays L) for natural sunscreen. J Food Agro Ind 2016;4:40-4. 